\title{
ELECTROCHEMICAL SURFACE OXIDATION OF GRAPHITE ELECTRODE AND ITS SUPERIOR SENSITIVE PLATFORM FOR ELECTROCHEMICAL SENSORS
}

\author{
R.B. Kohakade', E. Senthil Kumar', R.W. Gaikwad ${ }^{3}$, S. Raghu ${ }^{2, *}$ \\ and R.A. Kalaivani ${ }^{*}$ \\ ${ }^{1}$ Department of Chemistry, Vels University, Pallavaram, Chennai-600 117 (Tamilnadu) \\ India \\ ${ }^{2}$ Department of Vels Advanced Energy Research Center, Vels University, Pallavaram, \\ Chennai-600 117 (Tamilnadu)India \\ ${ }^{3}$ Department of Chemical Engineering, Pravara Rural Engineering College, Loni-413736 \\ (Maharashtra)India \\ *E-mail: rakvani@yahoo.co.in
}

\begin{abstract}
Here we first time report, the investigation of stable surface oxidized graphite electrode prepared via the anodic oxidation of graphite in different electrolyte medium such as $\mathrm{KOH}, \mathrm{H}_{2} \mathrm{SO}_{4}$ and $\mathrm{KH}_{2} \mathrm{PO}_{4}$. In the electrochemical surface oxidation route, high-quality graphene oxide was produced on the surface of the graphite rod. Formation of graphene oxide was proved with help of different techniques like X-ray diffraction, Raman spectroscopy analysis ,Fourier transform infrared spectroscopy etc. Synthesis produce was also distinguished with the help of scanning electron microscopy (SEM), etc. Simultaneous determination of $191 \mathrm{mV}$ Ascorbic acid (AA), 359mV Dopamine (DA) and $486 \mathrm{mV}$ Uric acid (UA) was done with the surface oxidized graphite electrode. Fast as well as sensitive electrochemical effect for finding of AA, DA and UA at potential between 0 to $1 \mathrm{~V}$ in the linear reaction series between $1 \mu \mathrm{M}$ to $10 \mathrm{mM}$ with detection boundary $(\mathrm{S} / \mathrm{N}=3)$ of $1.04 \mu \mathrm{M}(\mathrm{AA}), 0.1 \mu \mathrm{M}(\mathrm{DA})$ and $0.108 \mu \mathrm{M}(\mathrm{UA})$ were obtained. These results demonstrated that the electrochemically surface modified graphite electrode displayed a superior presentation along with elevated sensitivity and long-lasting stability.

Keywords:Fourier transforms infrared spectroscopy (FTIR), Electrochemical surface oxidized graphite, cyclic voltammetry, Differential pulse voltammetry.
\end{abstract}

(C) RASĀYAN. All rights reserved

\section{INTRODUCTION}

Graphene, is significant two-dimensional carbon formed by electronic superiority and elevated crystal, found as a quickly growing in the branch of material science. Graphene is slimmest recognized as well as powerful detected material on earth. ${ }^{1}$ Graphene is described as two-dimensional crystal, consist of a single layer of carbon atoms. ${ }^{2}$ It is interesting for hypothetical as well as experimental researchers in the universe. Graphite contains numerous graphene-sheets held collectively by weak Vander Waals forces. Thus accredit by a single layer of carbon atoms thickly enclosed in a comb like complex. ${ }^{3-5}$ Graphite from Nature, contains a heap of plane graphene-sheet, is reasonably priced and obtainable in huge amount. This regular carbon material is usually accessible and cheapest source for manufacturing of sheets of graphene in bulk quantity. Graphene-sheets is formed due to Mechanical cleavage of graphite. ${ }^{6}$ Due to huge van der Waals force, graphene-sheets are compact in graphite and due to this forces is the big difficulty for graphite exfoliation. Various chemical or physical routes have been found for graphene synthesis, hydrophobic characteristics of graphene synthesis are inadequate for mounting its applications. Planning of aqueous separated graphene sheet is of immense importance for basic and practical issues. ${ }^{7}$ Ascorbic acid (AA) is a familiar antioxidant, which plays a key in the human metabolic system. It's important physiological processes, like cell division, gene expression and activation of biological defense 
mechanisms. ${ }^{8}$ Dopamine is an imperative catecholamine neuron transmitter which is important for the operation of central nervous, and cardio vascular systems. ${ }^{9-12}$ Diseases such as schizophrenia or mental disorder disease, Parkinson's or brain disorder disease, and HIV infection many caused due to abnormal DA levels in human body. ${ }^{13-16}$ Diseases, such as hyperuricemia, gout and pneumonia may cause due to abnormal concentration levels of DA. ${ }^{17}$ AA, DA, and UA basically synchronize in biological samples, ${ }^{18}$ also it is useful to build up selective as well as a responsive way for Simultaneous determination of both analytical application and diagnostic investigation. Since AA, DA, and UA are mainly electrochemically energetic, electrochemical methods for Simultaneous determination acquire qualities of satisfaction, quickness as well as more sensitive. but, overlapping of the oxidation peaks of these three types at normal electrodes makes their Simultaneous determination highly complicated. To beat this difficulty, a variety of chemically modified electrodes has been developed. ${ }^{19-21}$ Due to its extensive potential window, comparatively inert electrochemistry and high electro catalytic activity for a number of redox reactions, ${ }^{22}$ carbon based nano materials like hollow nitrogen doped carbon microspheres are used continuously for Simultaneous determination of AA,DA,UA. ${ }^{23-25}$

We first time report that, the synthesis of stable surface oxidized graphite electrode in phosphate electrolyte medium and its superior catalytic behavior of AA,DA,UA.(Fig.-1., Scheme-1). We fabricated electrochemically surface oxidized graphite electrode via electrochemical oxidation of graphite and selfassembly method. The as-prepared electrochemically surface oxidized graphite electrode was characterized by single structural property and electrochemical properties, which provided it excellent performance as a promising electrode material. Compared with the bare, modified electrode exhibit much-advanced electro catalytic activities near to decomposition of AA, DA and UA. Hence, revise electrode based electrochemical sensor was designed for simultaneous determination of an AA, DA and UA with better selective as well as elevated responsive.

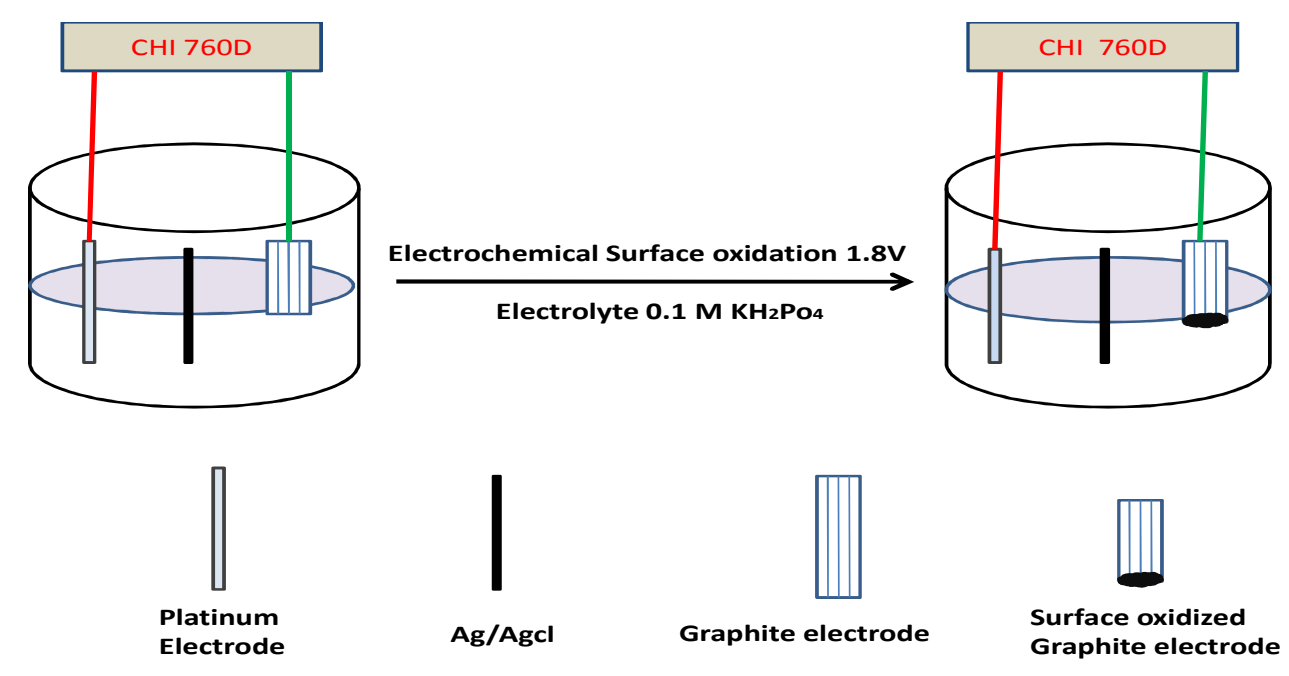

Fig.-1: Electrochemically surface oxidized graphite (ESOG) electrode via electrochemical oxidation of graphite and self-assembly method.

From linear sweep voltammetry scanning from 0 to $1.8 \mathrm{v}$ of three different electrolytes, ie. $\mathrm{KOH}, \mathrm{H}_{2} \mathrm{SO}_{4}$, $\mathrm{KH}_{2} \mathrm{PO}_{4}$, we studied that Potassium dihydrogen phosphate is a mild oxidizing agent and does not exfoliate, only surface modification takes place, So we have taken $\mathrm{KH}_{2} \mathrm{PO}_{4}$ as the electrolyte. The planned electrochemical oxidation mechanism showed that $\mathrm{PO}_{4}{ }^{-}$and $\mathrm{H}_{2} \mathrm{O}$ can be oxidized to form surface oxidized graphite rod, surface oxidized graphite rod was obtained by the formation of gaseous $\mathrm{H}_{2}$ and $\mathrm{O}_{2}$ within graphite rod. The graphite rod (Anode) and platinum (Cathode) were located vertically at bed and peak of the electrochemical cell, with $\mathrm{KH}_{2} \mathrm{PO}_{4}$ solution as an electrolyte. 


\section{Materials}

\section{EXPERIMENTAL}

Uric acid, Ascorbic acid, Dopamine, Potassium Hydroxide and Sulphuric acid this all were purchased from Sigma Aldrich. Doubled distilled $\mathrm{H}_{2} \mathrm{O}$ was used to prepare 0.1 M Phosphate Buffer Solution(PBS). Generally, all types of the electrochemical investigation were performed at a room temperature of $25 \pm 0.1$ Graphite rods were obtained from Sigma Aldrich, India. Potassium mono-hydrogen phosphate, dihydrogen phosphate etc. were purchased from Ranchem, Co. Ltd. India.

\section{Characterization}

Bruker AXS D8 Advance X-ray diffraction meter was used for X-ray powder distribution analysis of synthesized samples. D8 most Advance system was prepared with $2.2 \mathrm{~kW} \mathrm{Cu}$ anode X-ray tube and Lynx Eye position sensitive pointer. All powder patterns were obtained by $\mathrm{Cu} \mathrm{K \alpha}$ radiation $(\lambda=1.5406 \mathrm{~A})$. Scanning Electron Microscope (Hitachi S-3400 N) was used for observation of morphology and elemental composition of synthesized graphene. Perkin Elmer BX FT-IR spectrometer in the range of 4,000 to $400 \mathrm{~cm}^{-1}$ it was able to record of Fourier Transform Infrared (FT-IR) spectra of samples.

\section{Fabrication of Modified electrode}

We fabricated modified electrode via electrochemical oxidation of graphite and self-assembly method.

\section{Sample preparation}

In deionized $\mathrm{H}_{2} \mathrm{O}$ Stock solutions of the $10 \mathrm{mM}$ AA, DA, UA was kept ready at $4^{\circ} \mathrm{C}$. Concentrations of the AA, DA, and UA was lowered via diluting stock solution by $0.1 \mathrm{M}$ PBS and also freshly ready each and every day. Dopamine hydrochloride injection solution was initially diluted by 10 -fold along with deionized $\mathrm{H}_{2} \mathrm{OF}$ urthermore diluted by 1000 -fold with $0.1 \mathrm{M}$ PBS (pH 7.2). Concentrated standard solutions of Dopamine was mixed with diluted Dopamine injections. Urine of human being was taken from a disease free female and then filtered through $0.22 \mu \mathrm{m}$ membrane before any manipulations. Urine which was filtered was then diluted with 0.1 M PBS (pH 7.2) by 100-fold with the 0.1 M PBS (pH 7.2). Concentrated standard solutions of UA was mixed with diluted urine samples in recovery rate experiments.

\section{RESULTS AND DISCUSSION}

\section{Possible mechanism of electrochemically surface oxidized graphite electrode}

From linear sweep voltammetry scanning from 0 to $1.8 \mathrm{v}$ of three different electrolytes, ie. $\mathrm{KOH}, \mathrm{H}_{2} \mathrm{SO}_{4}$, $\mathrm{KH}_{2} \mathrm{PO}_{4}$, were studied that Potassium dihydrogen phosphate is a mild oxidizing agent and does not exfoliate, only surface modification takes place, so we have taken $\mathrm{KH}_{2} \mathrm{PO}_{4}$ as an electrolyte (Fig.-2).

Synthesis of the stable surface $(2 \mathrm{~mm})$ oxidized graphite electrode via the anodic oxidation of graphite in $\mathrm{KH}_{2} \mathrm{PO}_{4}$ solution, a short time at $1 \mathrm{hr}$. The proposed electrochemical oxidation mechanism showed that $\mathrm{PO}_{4}{ }^{-}$and $\mathrm{H}_{2} \mathrm{O}$ can be oxidized to form surface oxidized graphite rod, surface oxidized graphite rod was obtained by the formation of gaseous $\mathrm{H}_{2}$ and $\mathrm{O}_{2}$ within graphite rod.

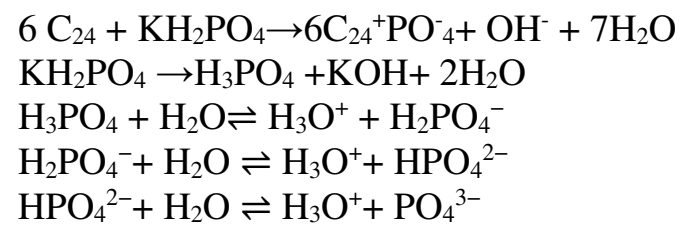

A possible mechanism of electrochemical oxidation: i) Oxidation at the edging sites as well as grain borders which help to depolarization and extension of the graphite layers, thus facilitates the oxidation of phosphate $\left(\mathrm{PO}_{4}{ }^{2-}\right)$ anions inside the graphitic layers. At some time, co-intercalation of $\mathrm{H}_{2} \mathrm{O}$ molecule with $\mathrm{PO}_{4}{ }^{2-}$ anions. (ii) self-oxidation of water and Phosphate $\left(\mathrm{PO}_{4}{ }^{2-}\right)$ anions create gaseous species such as $\mathrm{P}_{2} \mathrm{O}_{5}, \mathrm{O}_{2}$, and etc, as proof for the release of vital gas during electrochemical process. 
Chemical structure of electrochemically surface oxidized graphite rod was confirmed by FTIR spectral analysis in attendance of different oxygen functionalities, Fig.-3a proved that, the band at $1220 \mathrm{~cm}^{-1}$ correlate with the $\mathrm{C}-\mathrm{O}$ in the epoxide group, the bands at 1720 correlate to the $\mathrm{C}=\mathrm{O}$ carbonyl and 1618 $\mathrm{cm}^{-1}$ carboxyl and $\mathrm{C}=\mathrm{C}$ aromatic groups and the band at $3420 \mathrm{~cm}^{-1}$, correlate to the $\mathrm{O}-\mathrm{H}$ group. For ESOG, Figure-3b shows that $\mathrm{O}-\mathrm{H}$ band at $3430 \mathrm{~cm}^{-1}$ was oxidized by oxygenated functionalities. Here,XRD patterns of electrochemically surface oxidized of graphite were characteristic (Fig.-3b) Confirmation of the electrochemically surface exfoliation of graphite and formation of graphite oxide is proved with a peak at $2 \theta=25.54^{\circ}$, by a d-spacing of $0.34 \mathrm{~nm}$.

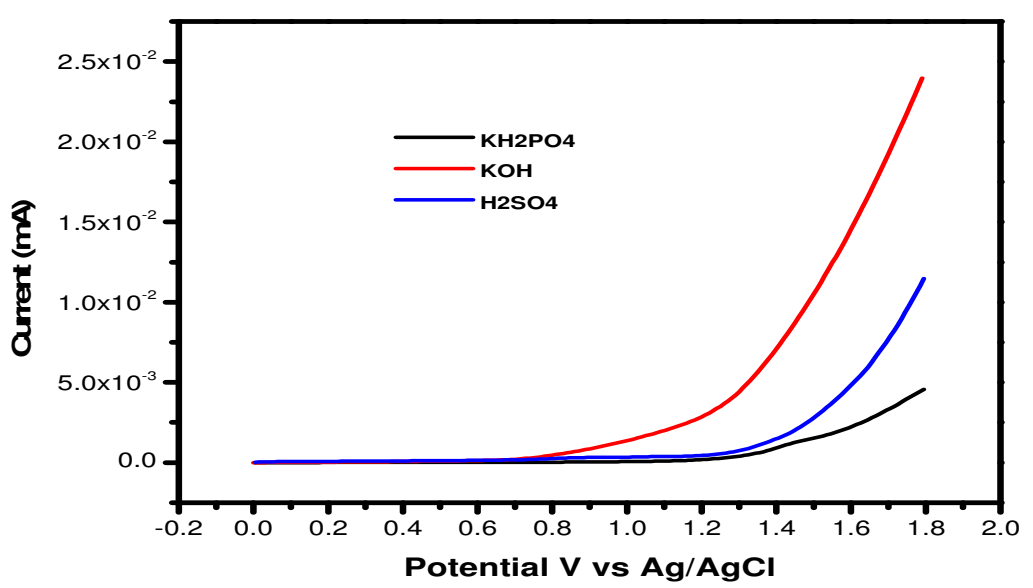

Fig.-2: LSV of the bare electrode in with $0.5 \mathrm{M}$ potassium dihydrogen phosphate, $0.5 \mathrm{M}$ of sulphuric acid and $1 \mathrm{M}$ of Potassium Hydroxide solution at a scan rate of $5 \mathrm{mV} / \mathrm{sec}$.

Raman spectrum of electrochemically surface oxidized graphite (Fig.-3c) The most important Raman features of the modified electrode are, $\mathrm{G}$ band $\left(1547 \mathrm{~cm}^{-1}\right)$, D band $\left(1351 \mathrm{~cm}^{-1}\right)$. The small concentration $\mathrm{D}$ peak in the spectrum near $1346 \mathrm{~cm}^{-1}$ shows the soaring superiority and little defects. The look of $\mathrm{D}$ peak might be recognized for edging of domain and domain borders. The widening of Bragg's peak indicates the development of crystalline graphite oxidized, whose dimension is measured by Scherer formula (eq.-1).

$\mathrm{D}=\mathrm{K} \lambda / \beta_{\mathrm{s}} \cos \theta$

Where, $\mathrm{D}=$ Average size of the crystal,

$\mathrm{K}=$ Scherer's constant depend on crystal shape,

$\lambda=$ Wavelength,

$\beta=$ Full peak width at half maximum,

$\theta=$ Diffraction angle.

By Using full width at half maxima (FWHM) of (111) peak, crystal sizes of ESOG is calculated are 2.01 $\mathrm{nm}$. The crystal size calculated from $\mathrm{I}_{\mathrm{D}} / \mathrm{I}_{\mathrm{G}}$ ratio using the formula (eq.-2).

$\mathrm{La}=2.4 \times 10^{-10} \lambda^{4}\left[\mathrm{I}_{\mathrm{D}} / \mathrm{I}_{\mathrm{G}}\right]^{-1}$

Were, La is $3.8 \mathrm{~nm}$ respectively.

The SEM describes the surface analysis of prepared modified electrode, the Flaky texture of modified electrode was obtained by incomplete exfoliation. This suggests that incomplete exfoliated structure and reflects its coated microstructure huge inter-layer spacing as well as bulky multi-layer stacks, as noted in the literature. (Fig.-3d) shows the Scanning electron microscope images of electrochemically surface oxidized graphite oxide respectively. From figures, it shows that, the surface oxide graphite oxidize sheets 
were translucent as well as wrinkly in the environment. This wrinkled graphite oxide is very advantageous to maintain an elevated surface region of the electrode hence the sheets cannot willingly fall down reverse to a graphitic structure consisted of randomly aggregated slim shape crumpled sheets that are strongly allied with them self, for the formation of disordered solid.
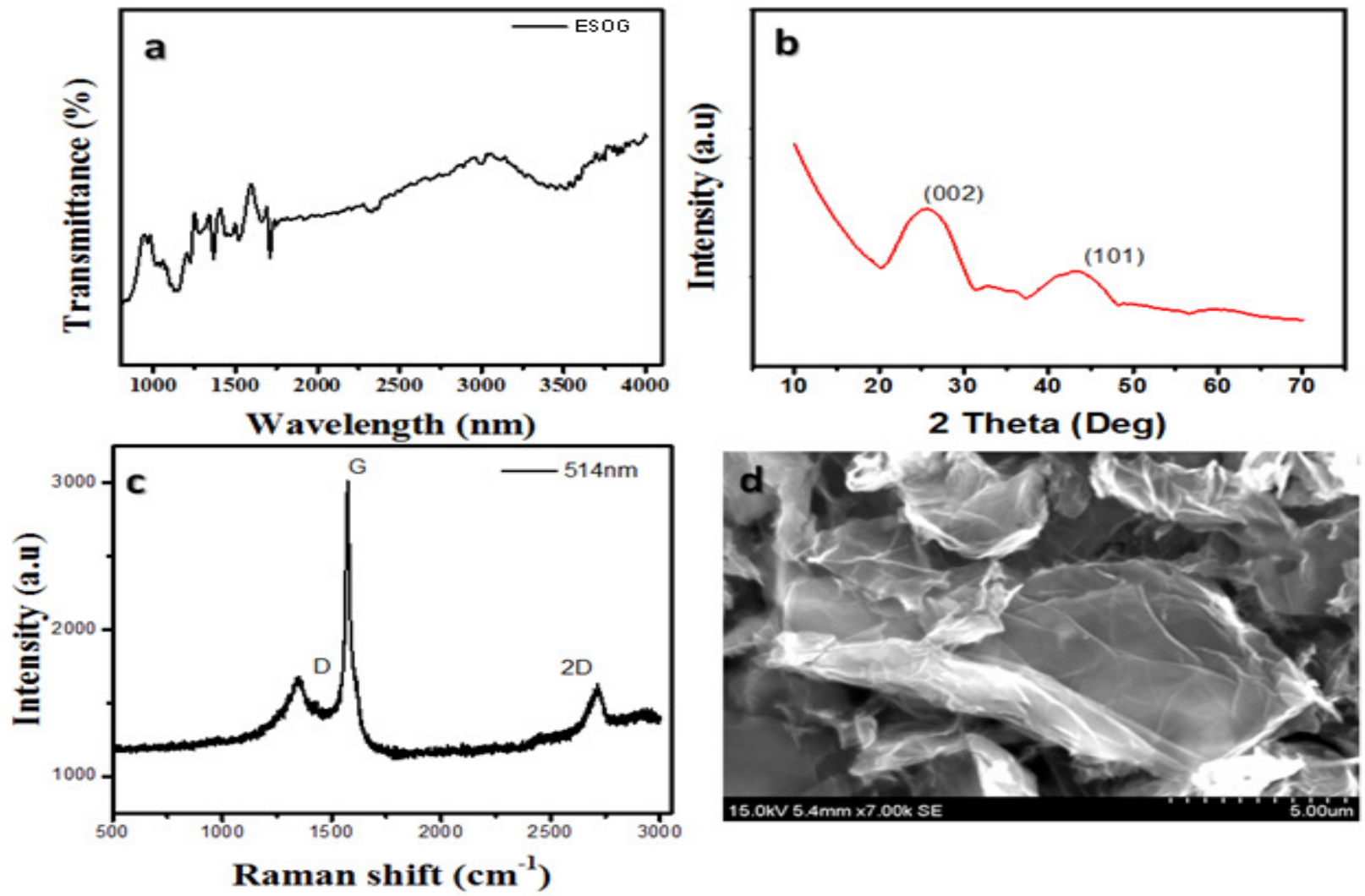

Fig.-3: FTIR,XRD, Raman Spectroscopy,SEM.

\section{Cyclic voltammetry $(\mathrm{CV})$ response of the AA, DA and UA on the modified electrode}

From various types of supporting electrolytes with the maximum sensor, the response was received from 0.1M PBS and selected as the sustaining electrolyte. CVs of the bare and ESOG modified electrode in 0.1M PBS (pH.7.2) which contains $1 \mathrm{mM}$ AA, $0.5 \mathrm{mM}$ DA and $1 \mathrm{mM}$ UA are exposed in Fig. $-4 a$. No anodic peak was formed in the bare electrode $($ Ipa $=4.038 \mu \mathrm{A})$. However, an anodic peak obviously appeared on ESOG electrode appeared at $(\mathrm{Ipa}=13.32 \mu \mathrm{A})$ electrode in the medium containing in $0.1 \mathrm{M}$ PBS (pH 7.2) at a scan rate of $50 \mathrm{mVs}-1$ (Fig.-3a). CV responses of ESOG toward, AA, DA and UA are shown in Fig.-4b So that ESOG electrode AA, DA and UA show broad oxidation peaks with peak potentials at 191, 359and $486 \mathrm{mV}$, respectively (Fig.-4b). For Dopamine, a pair of redox peaks appeared at $359 \mathrm{mV}$ and $293 \mathrm{mV}$, corresponding to the two electrons oxidation of Dopamine to odopaminoquinone and subsequent reduction of o-dopaminoquinone to DA, respectively. The $\Delta \mathrm{Ep}$ is 66 $\mathrm{mV}$ and oxidation climax current is 2.5 times more than that obtained at ESOG, this shows superb electro catalytic activities of ESOG toward DA. The oxidation climax currents of Dopamine constantly enlarges with increasing scan rate at $0.1 \mathrm{M}$ PBS.

The effect of various scan rates of the ESOG electrode in presence of (a) $1 \mathrm{mM} \mathrm{AA}$, (b) $0.5 \mathrm{mM}$ DA and (c) $1 \mathrm{mM}$ UA are shown in Fig.-4.

The Randle equation for identification of reversible process of the modified electrodes can be detected as per given below: 
$i p=2.69 \times 10^{5} \mathrm{An}^{3} / 2^{1 / 2} \mathrm{Dv}^{1 / 2}$

Where,

$i p=$ peak current,

$\mathrm{A}=$ Area of electrode $\left(\mathrm{cm}^{2}\right)$,

$\mathrm{n}=$ Number of electron transfer,

$\mathrm{D}=$ Diffusion coefficient $\mathrm{D}$,

$\mathrm{C}=$ Concentration,

$v=$ Scan rate $v$.
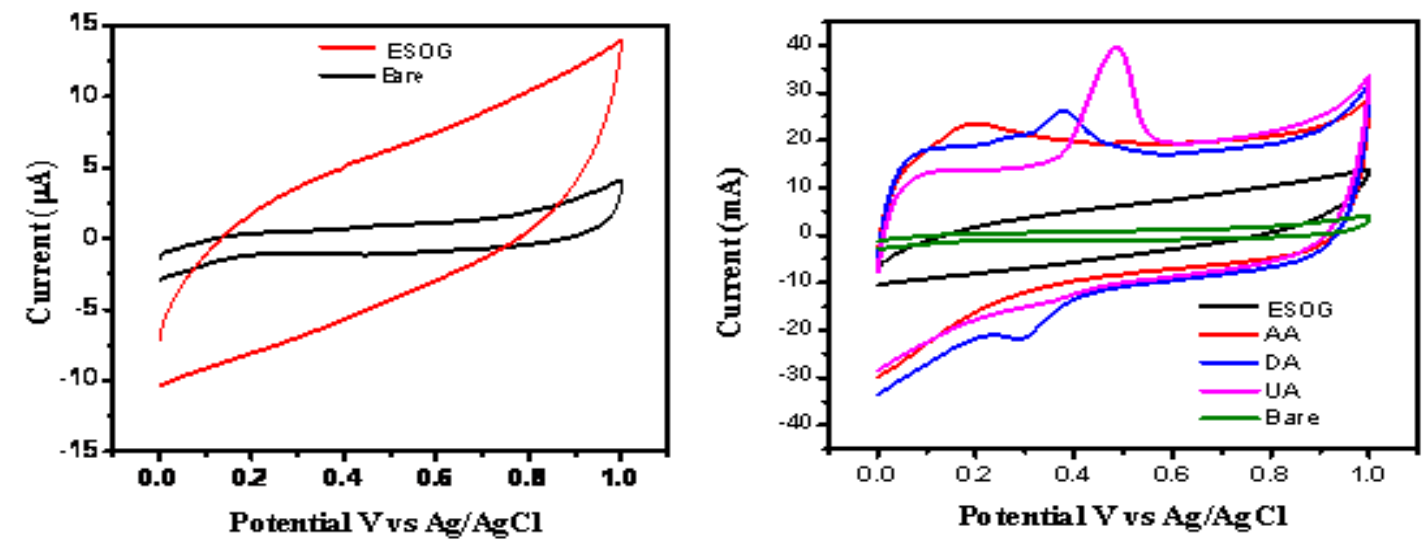

Fig.-4(a): CVs of bare and ESOG in 0.1M PBS (pH.7.2) at scan rate of $50 \mathrm{mV} / \mathrm{sec}$.

Fig.-4(b): shows the effect of various scan rates on the current responses of the ESOG electrode in presence of containing (a) $1 \mathrm{mM}$ Ascorbic acid (AA), (b) $0.5 \mathrm{mM}$ Dopamine (DA) and (c) $1 \mathrm{mM}$ Uric acid (UA).

The directly proportional of anodic climax current to the square root of the scan rate from $5 \mathrm{mV}$ to 100 $\mathrm{mV}$, as AA, Dopamine, and UA while the linear regression equation was articulated as a Ipa $=4.9106 \mathrm{x}$ $7.3218 \mathrm{R}=0.9958, \mathrm{Ipa}=3.0614 \mathrm{x}-1.5615 \mathrm{R}=0.9976$, Ipa $=5.685 \mathrm{x}+1.0404 \mathrm{R}=0.9983$ (Ipa in $\mu \mathrm{A}$, in $v$ $\mathrm{Vs}^{-1}$ ), signifying that ESOG has undergoes an diffusion controlled method. From Randles equation (2), the diffusion coefficient of AA, DA and UA was measured and originate to be $1.305,0.49$ and 5.83. Anodic peak potential at the ESOG was slightly moved positively with amplifying in scan rate.

\section{Simultaneous determination of AA, DA and UA}

Individual detection of AA, DA and UA at ESOG modified electrode was performed by Differential pulse voltammetry (DPV). Current increases as the concentration rises and the oxidation potential do not changes it remains constant. The linear relation among the peak currents and concentrations of AA, DA and UA were $I p a=49.180\left(R^{2}=0.9958\right), I p a=47.071-0.6997\left(R^{2}=0.9965\right)$ and $I p a=59.720+8.1096\left(R^{2}=\right.$ 0.9983 ) in the ranges of $1.04-10.0821 \mu \mathrm{M}, 0.1-99.78 \mu \mathrm{M}$, and $0.108-100.21 \mu \mathrm{M}$ respectively, and the detection restrictions were $1.04 \mu \mathrm{M}, 0.1 \mu \mathrm{M}$, and $0.108 \mu \mathrm{M}$. Wide linear range with higher sensitivity, shows the superb electrochemical activity of modified electrode. Simultaneous detection of AA, DA and UA was done and its outcome is given in Fig.-6.

Three distinct oxidation peaks were seen. The line calibration curves between their oxidation peak currents with their concentrations and with correlation coefficients of $0.9958,0.9965$ and 0.9983 , correspondingly, and with their detection limits $1.04 \mu \mathrm{M}, 0.1 \mu \mathrm{M}$, and $0.108 \mu \mathrm{M}$.

\section{Reproducibility and stability of ESOG}

Reproducibility of ESOG electrode it was studied by investigating the response to the combination of a solution of AA, DA and UA in 0.1 M PBS ( $\mathrm{pH}=7.2)$ with modified electrodes formed by the same 
method. Moreover, the stability of electrode was also the key factor to judge. Before carrying out the experiment the modified electrode was kept for 21 days at normal room temperature. The reusability of ESOG was projected by studying the DPV results of a mixture containing $1.05 \mathrm{mM}$ Ascorbic acid, 0.1 $\mathrm{mM}$ Dopamine and $0.5 \mathrm{mM}$ uric acid in $0.1 \mathrm{M}$ PBS solution $(\mathrm{pH} 7.2)$ with five electrodes formed by a similar condition. The relative standard deviations of the oxidation peak currents are $3.28 \%$ of Ascorbic acid, $1.93 \%$ of Dopamine and $2.26 \%$ of Uric acid. The modified electrode was kept at $25{ }^{\circ} \mathrm{C}$ room temperature for a week before carrying out the experiment, for checking the stability of ESOG electrode.
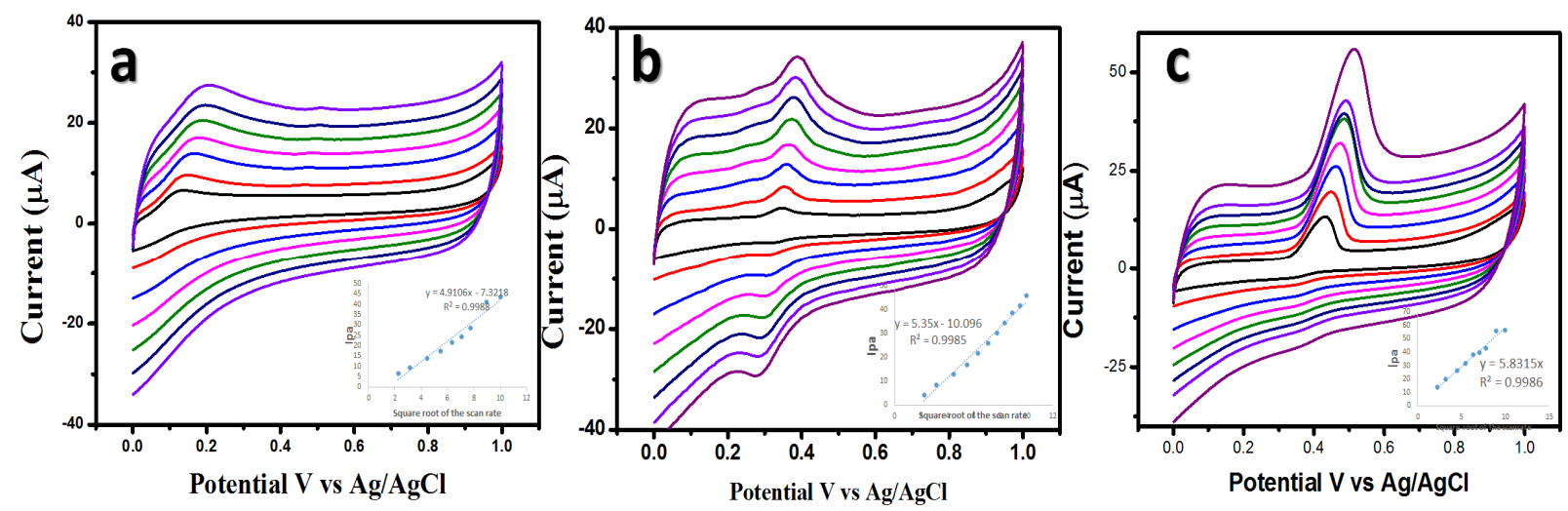

Fig.-5: The effect of variour scan rates on the current responses of the ESOG electrode (a)1mM Ascorbic acid (AA), (b) $0.5 \mathrm{mM}$ Dopamine (DA) and (c) $1 \mathrm{mM}$ Uric acid (UA) in $0.1 \mathrm{M}$ PBS.

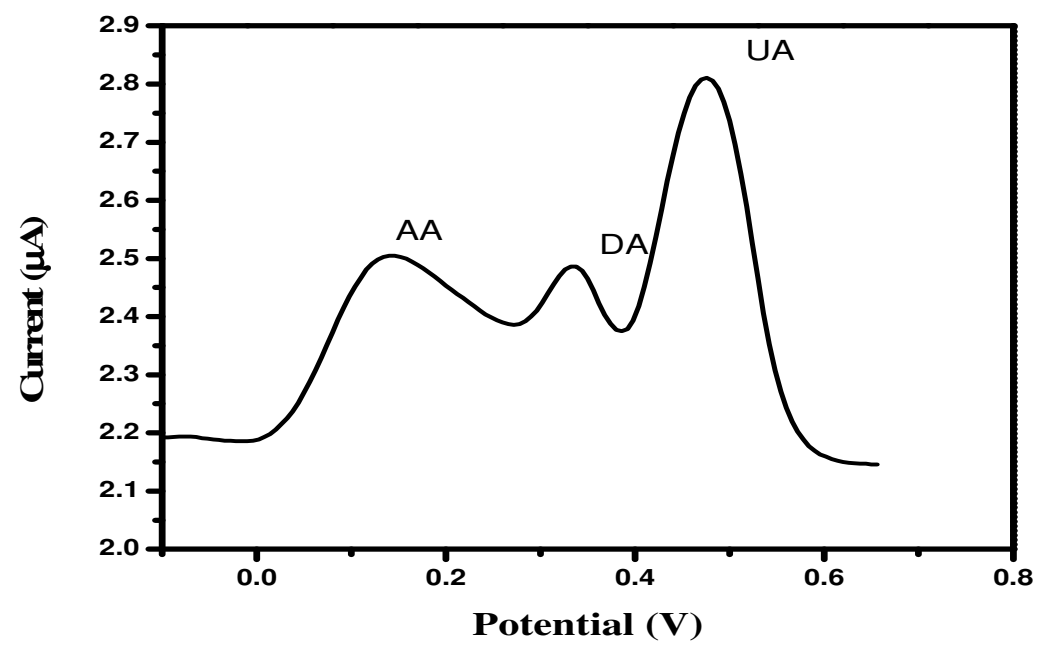

Fig.-6: DPV result of $1 \mathrm{mM}$ AA, $0.5 \mathrm{mM}$ DA and $1 \mathrm{mM}$ UA in $0.1 \mathrm{M}$ PBS solution (pH 7.2) on ESOG at $50 \mathrm{mV}$ pulse amplitude.

The climax current intensity is decayed by Ascorbic acid 4.5\%, Dopamine 3.7\% and Uric acid 3.9\%, representing a storage stability of the modified electrode. Above result shows that the modified electrode shows excellent stability well reusability.

\section{CONCLUSION}

Three medium has been experienced in favor of electrical exfoliation and oxidizes of graphite for Preparation of electrochemically surface oxidize graphite and its economically low cost. amongst media used, the PBS with $\mathrm{pH} 7.2$ shows best results for producing higher oxidization and surface oxidize graphite than the $\mathrm{H}_{2} \mathrm{SO}_{4}$ and $\mathrm{NaOH}$. The modified electrode not only detects separately but three 
compounds were detected Simultaneously. While with Comparison to the ordinary electrode, the modified electrode shows good electrocatalytic activities for the oxidation of AA,DA and UA shows superior sensitivity and selectivity. Detection of real samples was very superiorly carried out by the modified electrodes.

1. A. K. Geim, Science, 324, 1530(2009)

2. D.Li , R.B Kaner, Nat Nanotechnol, 3,101(2008).

3. K.S Novoselov, A.K Geim, S.V Morozov, D. Jiang, Y. Zhang, S.V Dubonos, I.V Grigorieva, A.A Firsov. Science, 306, 666(2004).

4. C. Berger, Z. Song, X. Li, X. Wu, N. Brown, C. Naud, D. Mayou, T. Li, J. Hass, A.N Marchenkov, E.H Conrad, Science, 312,1191(2006).

5. C. Lee, X. Wei, J.W Kysar, J. Hone, Science, 321, 385(2008).

6. T.A Land, T. Michely, R.J Behm, J.C Hemminger, G. Comsa, Surface Science, 264, 261(1992).

7. X. Qi, K.Y Pu, H. Li, X. Zhou, S. Wu, Q.L Fan, B. Liu, F. Boey, W. Huang, H. Zhang, Angewandte Chemie International Edition, 49, 9426(2010).

8. Y. Su, Y. Zhang, X. Zhuang,S. Li , D. Wu, F. Zhang, X. Feng, Carbon, 62, 296(2013).

9. W.S Hummers, R.E Offeman, Journal of the American Chemical Society, 80, 1339(1958).

10. C. H Choi, S. H Park, \& S.I Woo, ACS nano,6, 7084(2012).

11. S. Zhao, J. Liu, C. Li, W. Ji, M. Yang, H. Huang, Y. Liu, Z. Kang, ACS Applied Materials \& Interfaces, 6, 22297(2014).

12. X. Zhuang, D. Gehrig, N. Forler, H. Liang, M. Wagner, M. R. Hansen, F. Laquai, F. Zhang, X. Feng, Advanced Materials, 27, 3789(2015).

13. D.S Yang, D. Bhattacharjya, S. Inamdar, J. Park, J.S Yu, Journal of the American Chemical Society, 134, 16127(2012).

14. J. Wang, Z. Xu, Y. Gong, C. Han, H. Li, Y. Wang, ChemCatChem, 6, 1204(2014).

15. L. Chen, R. Du, J. Zhu, Y. Mao C. Xue, N. Zhang, Y. Hou, J. Zhang, T. Yi, Small, 11, 1423(2015).

16. J.M Zen, P.J Chen, Analytical Chemistry, 69, 5087(1997).

17. H. Wang, P. Jiang, X. Bo, L. Guo, Electrochimica Acta, 65, 115(2012).

18. W. Zhang, R. Yuan, Y.Q Chai, Y. Zhang, S.H Chen. Sensors and Actuators B: Chemical, 166, 601(2012).

19. R.L McCreery, Chem. Rev, 108, 2646(2008).

20. Y. Liu, J. Huang, H. Hou, T. You. Electrochemistry Communications, 10, 1431(2008).

21. Y. Zhao, Y. Gao, D. Zhan, H. Liu, Q. Zhao, Y. Kou, Y. Shao, M. Li, Q. Zhuang, Z. Zhu, Talanta, 66, 51(2005).

22. C. Xiao, X. Chu, Y. Yang, X. Li, X. Zhang, J. Chen, Biosensors and Bioelectronics, 26, 2934(2011).

23. C. Wang, R. Yuan, Y. Chai, Y. Zhang, F. Hu, M. Zhang, Biosensors and Bioelectronics, 30, 315(2011).

24. J. Li, X. Wu, Y. Yu, S. Le. Journal of Solid State Electrochemistry, 13, 1811(2009).

25. F. Gao, X. Cai, X. Wang, C. Gao, S. Liu, F. Gao, Q. Wang. Sensors and Actuators B: Chemical, 186, 380(2013).

[RJC-1881/2017] 